\title{
LEFT VENTRICULAR ANEURYSMS OF UNCERTAIN ÆTIOLOGY
}

BY

\author{
W. A. POCOCK, W. P. COCKSHOTT, P. J. A. BALL, AND R. E. STEINER \\ From the Departments of Medicine (Clinical Cardiology) and Radiology, Postgraduate Medical School of London; and \\ University College Hospital, Ibadan, Nigeria \\ Received June 22, 1964
}

An unusual type of annular, subvalvular left ventricular aneurysm has recently been described in Nigerians by Robertson and Jackson (1960) and Abrahams et al. (1962). A search revealed reports of similar cardiac aneurysms of unknown ætiology (Corvisart, 1813; Hunter and Benson, 1933; Berlin and Hallén, 1938; Burn, Hollander, and Crawford, 1943; Higginson and Keeley, 1951; Brink and Barnard, 1954; Clearkin and Bunjé, 1955; Lurie, 1960). With one possible exception (Martin, 1946) all the cases hitherto described have been Negroes. The modes of presentation have been diverse. Congestive cardiac failure, pulmonary œdema, or sudden death from pericardial tamponade following rupture of an aneurysm have been reported frequently. Other cases have been asymptomatic, and an abnormal radiological cardiac outline has led to their detection. A large proportion of these patients have had murmurs of mitral incompetence, and the regurgitation has been confirmed by angiocardiograms in some. Necropsy has revealed stretching and dilatation of the mitral ring produced by these aneurysms due to their extension in an annular fashion around the valve ring. In the majority of patients the electrocardiogram has shown surprisingly little abnormality even in the presence of multiple large aneurysms. Generalized low voltage, slight S-T segment depression with flat or inverted $T$ waves in the limb leads and left ventricular chest leads were usually recorded (Abrahams et al., 1962).

This paper describes two further patients with subvalvular aneurysms, one of whom is a European. The electrocardiogram in both patients suggested myocardial infarction. In the second patient interesting auscultatory features were present, which have not previously been described in association with these cardiac aneurysms.

\section{CASE RePORTS}

Case 1. A.I. (U.C.H. No. 101893), a Nigerian Yoruba farmer aged 18, was referred in June 1963 from a Mission Hospital near his home. He complained that for four months he had had anterior chest pain, at first with aching and heaviness in both arms, but more recently only in the chest and left shoulder. Initially the pain had been felt only when he walked uphill, but in the last two months he claimed never to have been without it, and to have been increasingly breathless. For several days pain had prevented his lying down or eating a full meal. He could recall no previous attacks of pain, and could give no useful information about his near relations.

Examination showed him to be orthopnoic and anxious. His temperature was $100 \cdot 4^{\circ} \mathrm{F}$. $\left(38^{\circ} \mathrm{C}\right.$.). There was a sinus tachycardia of 130 a minute. The venous pressure was raised $5 \mathrm{~cm}$. above the sternal angle, and there were râles at the lung bases. Blood pressure was $115 / 75 \mathrm{~mm}$. $\mathrm{Hg}$. The apex beat was palpable in the 4th left interspace in the mid-clavicular line. No murmurs were heard, and there was no evidence of pulmonary hypertension.

Fluoroscopy at that time showed aneurysmal bulging of the upper border of the left ventricle without detectable systolic expansion. The left atrium did not appear to be enlarged; no calcification was seen within the cardiac shadow (Fig. 1). 


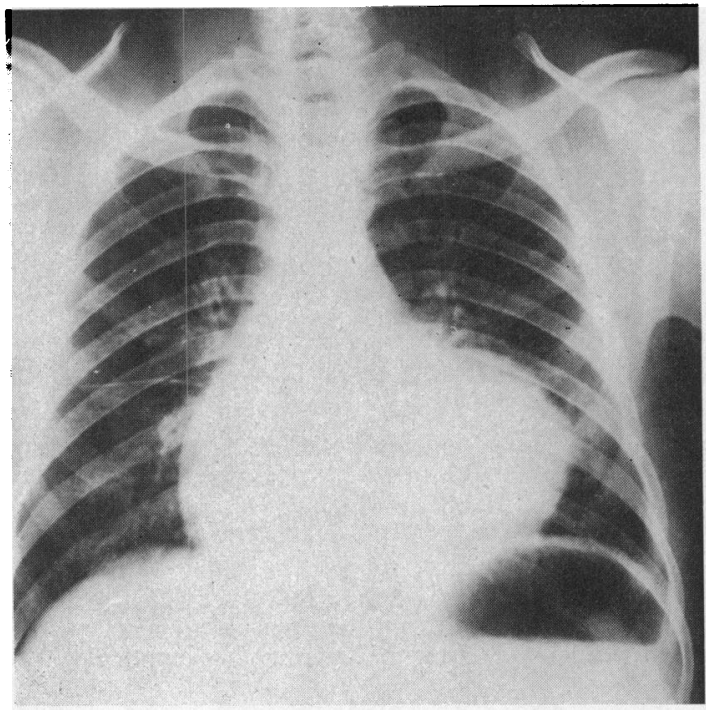

FIG. 1.-Chest radiograph of Case 1 two days after admission, showing the abnormal contour of the left border of the heart.

FIG. 2.-The electrocardiogram of Case 1, on admission (A); after two weeks (B); and after four weeks (C), showing appearances suggestive of subepicardial antero-lateral infarction.

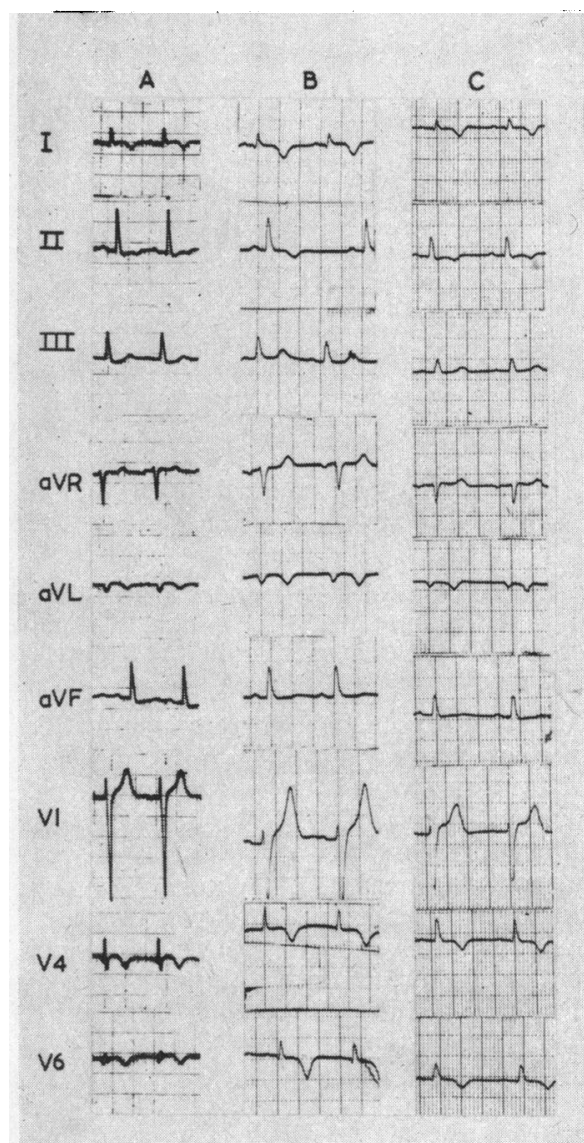

The electrocardiogram showed appearances suggestive of an acute sub-epicardial antero-lateral infarction (Fig. 2). The hæmoglobin was $11.5 \mathrm{~g} . / 100 \mathrm{ml}$. and white blood count $13,000 / \mathrm{c}$. $\mathrm{mm}$. (polymorphs $80 \%$ ). Enzyme tests were not done, but the Kahn test was negative.

He was considered on this evidence to have a left ventricular aneurysm, and was treated with morphine, digoxin, heparin, and phenindione. He became afebrile after three days and remained so. On the day after his admission a pericardial rub was heard, which persisted for two days. His heart failure and tachycardia disappeared gradually over ten days. The electrocardiogram showed little change over a period of one month, though the small q wave in V5 and V6 disappeared (Fig. 2C). On July 12, nearly three weeks after admission, he had another brief attack of chest pain, without fever or tachycardia.

Left ventricular angiography was carried out on July 23 , by retrograde catheterization from the femoral artery. Screening at that time showed paradoxical systolic expansion of the aneurysm. The left ventricular chamber was displaced by the aneurysm, so that the tip of the catheter when in the ventricle lay nearer to the mid-line than normal. The aneurysm filled with contrast medium through an antero-lateral communication high in the body of the ventricle, and remained full after the contrast had left the ventricle (Fig. 3). Its wall was approximately $1 \mathrm{~cm}$. thick. A small amount of reflux occurred into the left atrium. Both coronary arteries filled; the circumflex branch of the left coronary artery was stretched over the aneurysm, but not occluded.

He was discharged free of symptoms in August.

Case 2. M.D., a European boy, aged 18 years, was seen in November 1962 by Dr. R. L. Ward, Blackburn Royal Infirmary, complaining of palpitations for the previous six months. Although initially present only on strenuous exertion they later occurred also at rest. At the same time he found he was exhausted at the end of his day's work as an apprentice butcher. He also noticed shortness of breath on moderate exertion. Since December he had occasionally experienced a dull præcordial pain, either at rest or on effort, which radiated to the left axilla or scapula. It did not appear to be ischæmic in nature. 


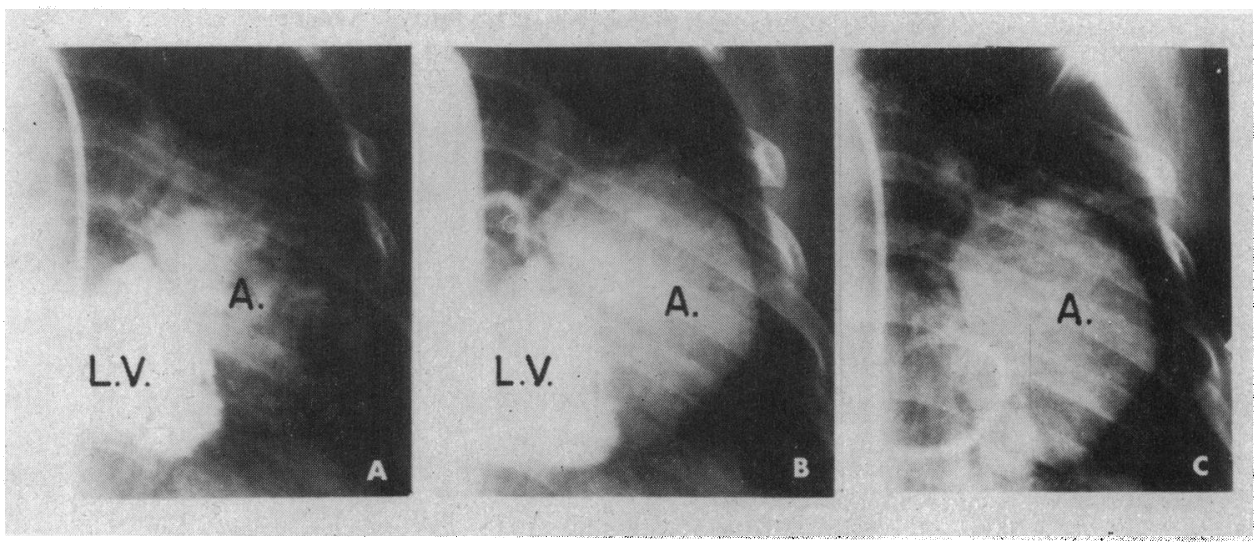

Fig. 3.-Case 1. Left ventricular angiogram (frontal projection). A, 1.3 sec.; B, $2 \cdot 3 \mathrm{sec}$; C, $5 \mathrm{sec}$. after injection of the contrast medium. The aneurysm (A.) fills from the upper border of the left ventricle (L.V.), and the contrast remains in the aneurysm after the ventricle has emptied.

There was no history of any previous illness. Family history was negative.

An electrocardiogram in November 1962 suggested a posterior myocardial infarction, and he was kept in bed for four weeks. Five subsequent electrocardiograms showed no change. In May 1963, he was referred to Professor J. F. Goodwin, and was admitted to Hammersmith Hospital for further investigation.

On examination, he was a well-built boy with no evidence of anæmia, cyanosis, or clubbing. There were no xanthomata present. All the peripheral pulses were normal. The blood pressure was $145 / 64 \mathrm{~mm}$. $\mathrm{Hg}$, and the jugular venous pressure was normal.

The apex beat was within the mid-clavicular line, but was rather forceful in character and suggestive of left ventricular hypertrophy. There was a clearly palpable mid-systolic impulse at the apex. On auscultation he had a mid-systolic click followed by a grade 2 late systolic murmur which was maximal at the

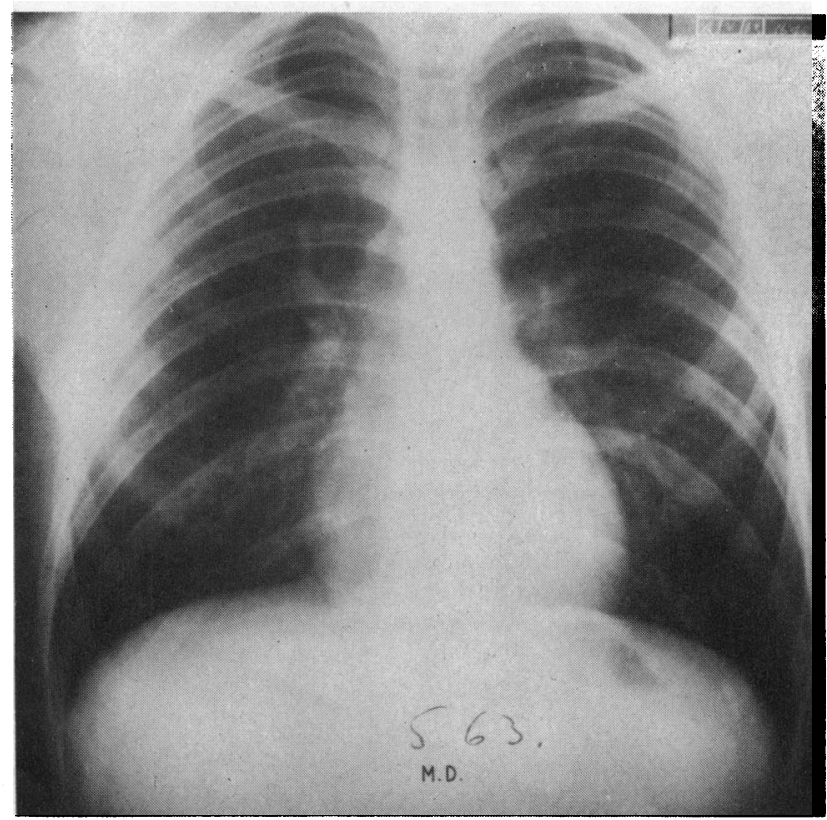

FIG. 4.-Six-foot postero-anterior radiograph showing normal cardiac contour in Case 2. 

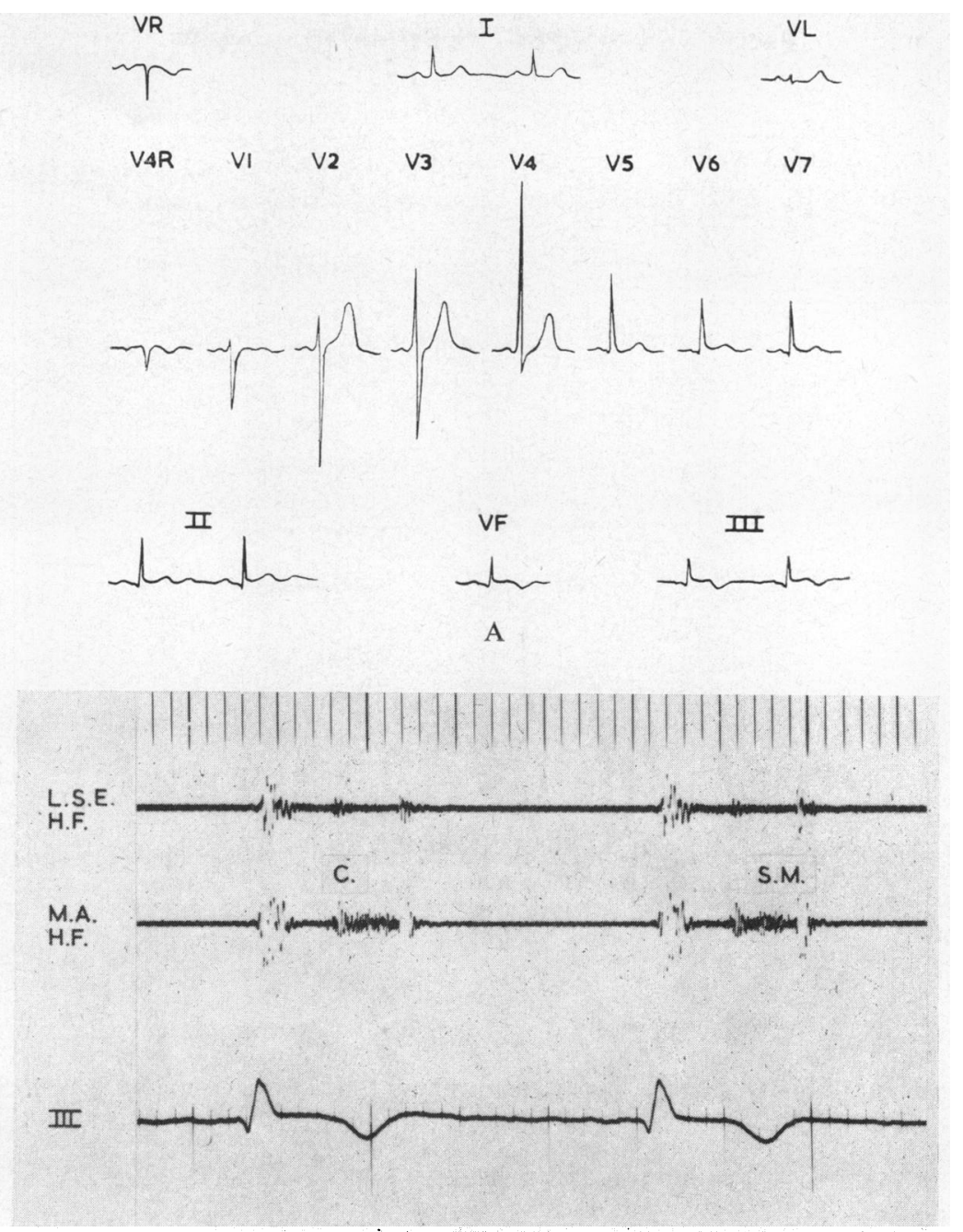

B

FIG. 5.-Case 2. (A) Electrocardiogram showing appearances suggestive of posterior infarction (see text). (B) Phonocardiogram showing mid-systolic click (C.) and late systolic murmur (S.M.). L.S.E. = left sternal edge. M.A. $=$ mitral area. H.F. $=$ high frequency. III = electrocardiogram standard lead III.

apex and also audible at the left lower sternal edge. The systolic murmur extended to the second heart sound. There was a soft apical third heart sound but no diastolic murmurs were audible. The second heart sound was normal.

The remainder of the physical examination was negative.

A radiograph of the chest was normal (Fig. 4).

The electrocardiogram (Fig. 5A), which was unchanged from November, showed S-T segment elevation in leads II, III, VF, V6, and V7, and inverted T waves in leads III and aVF. The electrical axis was normal. An effort test showed no change in the $S-T$ segments or $T$ waves. The $P$ waves became inverted and this was associated with slight shortening of the $P-R$ interval, consistent with a nodal rhythm.

A phonocardiogram (Fig. 5B) confirmed the auscultatory findings. High frequency vibrations of a plateau-shaped murmur commenced with the mid-systolic click and extended to the second heart sound. This murmur was thought to indicate mild mitral incompetence and additional phonocardiographic studies were performed to confirm this.

Amyl Nitrite (Fig. 6A): Within the first 20 seconds after inhalation of amyl nitrite the murmur had 


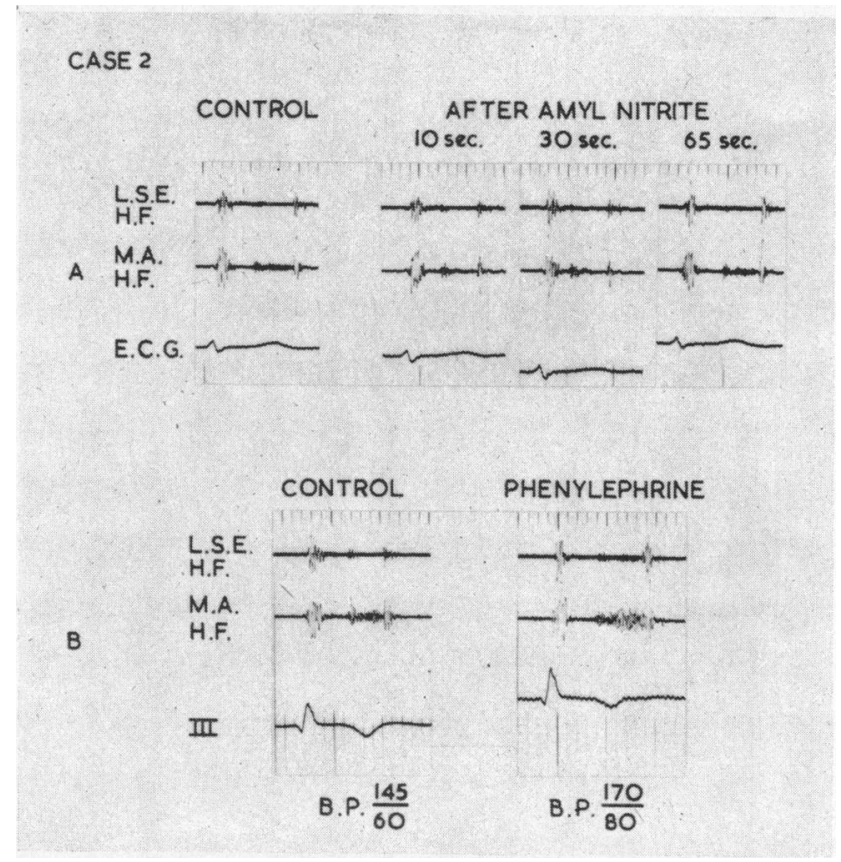

FIG. 6.-Case 2. (A) Phonocardiogram before, and at intervals after, the inhalation of amyl nitrite showing the decrease in intensity of the murmur (see text). (B) Phonocardiogram showing the increased intensity of the late systolic murmur after intravenous phenylephrine, which has caused the systemic blood pressure to rise (see text).

decreased considerably in intensity, virtually disappearing. By 60 seconds it had returned to its former intensity.

Phenylephrine (Fig. 6B). During the hypertensive phase following the intravenous injection of $0.5 \mathrm{mg}$. of phenylephrine the systolic murmur increased greatly in intensity, the configuration and position in late systole remaining unchanged.

The findings were consistent with mitral incompetence (Barlow and Shillingford, 1958; Vogelpoel et al., 1959; Endrys and Bártová, 1962).

Further Investigations. The erythrocyte sedimentation rate was $3 \mathrm{~mm}$. in the first hour (Westergren), the hæmoglobin $14 \mathrm{~g}$. $/ 100 \mathrm{ml}$, the white cell count 5000/c. mm., and the serum cholesterol 210 $\mathrm{mg}$. $/ 100 \mathrm{ml}$. Urea and electrolytes, serum protein electrophoresis, and urine analysis were also normal. The Wassermann reaction was negative.

A provisional clinical diagnosis of mild mitral incompetence was made, the ætiology of which was obscure. It was thought that the unusual electrocardiogram might reflect an anomaly of the coronary arteries.

Cardiac Catheterization and Angiography. Using the Seldinger technique retrograde left ventricular catheterization was performed. Cine-angiography in the lateral position showed mitral incompetence of moderate degree. In addition a small diverticulum was demonstrated arising from the left ventricle immediately below the posterior aspect of the mitral valve ring. This filled and emptied freely with each cardiac cycle. An injection of hypaque immediately above the aortic valve showed good filling of the coronary arteries and these appeared normal. There was no aortic incompetence.

Biplane left ventricular angiography performed one week later confirmed the previous findings, and, in addition, the antero-posterior projection showed two further left ventricular expansions close to the mitral ring (Fig. 7A and B).

The mitral valve cusps appeared to be distorted.

Right heart catheterization was normal. The following pressures (in $\mathrm{mm} . \mathrm{Hg}$ ) were recorded: Mean right atrial, 3 ; right ventricular, 22/-2/4; main pulmonary artery, 20/9; mean pulmonary wedge, 8 . Calculated pulmonary vascular resistance: less than 1 unit. The cardiac output was 6.8 litres a minute.

Management. As the boy was relatively asymptomatic, the natural history of the disease unknown, and multiple aneurysms were present, it was thought that the hazards of surgical excision were unjustified. He was advised to avoid undue exertion in view of the risk of rupture of the aneurysms. Should he deteriorate 


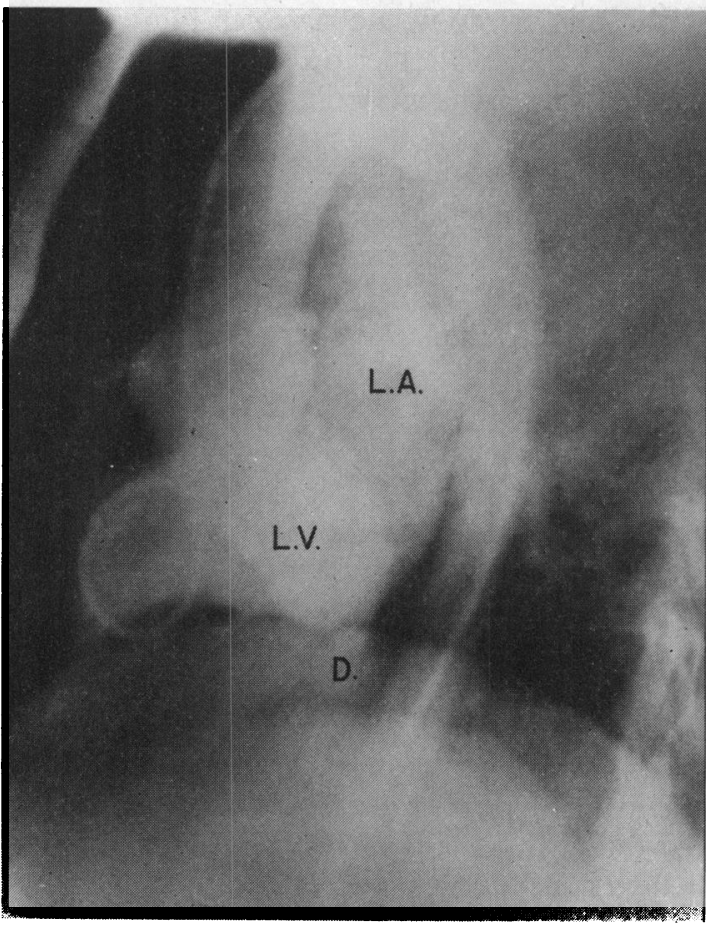

A

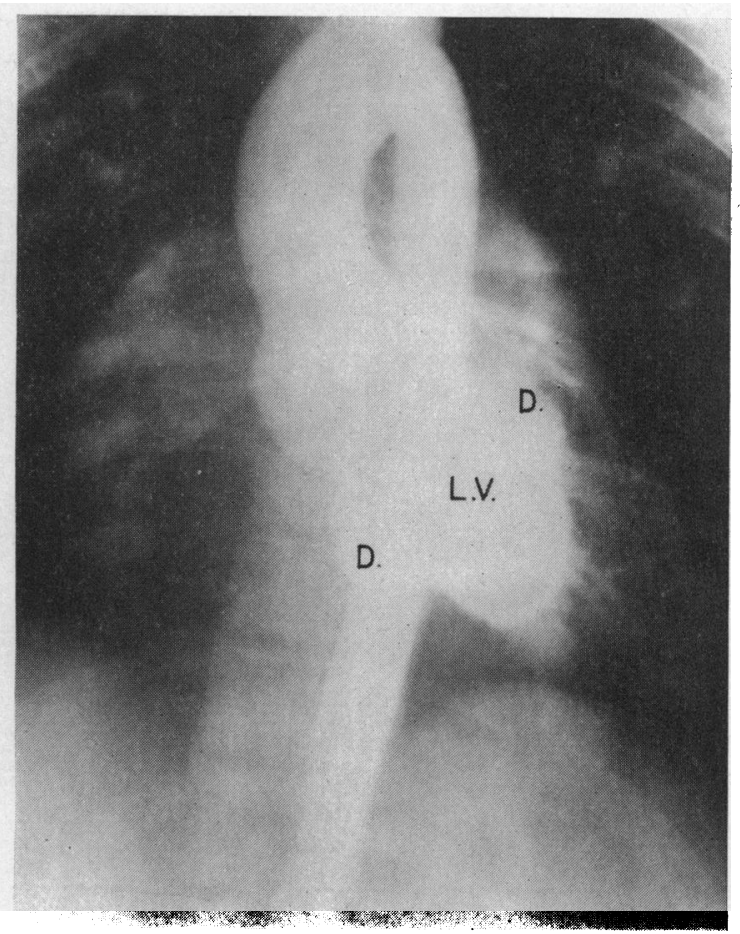

B

FIG. 7.-(A) Biplane left ventricular angiogram (lateral projection) showing diverticulum (D.). Contrast medium fills the left atrium (L.A.) from the left ventricle (L.V.) indicating mitral regurgitation. (B) Biplane left ventricular angiogram (frontal projection) showing aneurysmal bulges (D.) in region of mitral valve ring. (L.V. = left ventricle).

because of an increase in the size of the aneurysms or in the degree of mitral incompetence, the question of surgery will be reconsidered.

\section{Discussion}

In the absence of direct examination of the heart, it is not possible to establish with certainty the nature of the aneurysm in either case, but the evidence suggests that both are of the annular, subvalvular variety that has been described in Negroes. The characteristic situation, origin by a narrow neck, and the multiplicity of aneurysms in Case 2, are in favour of the diagnosis. There is no reason to suspect that any of the rarer causes of cardiac aneurysms, such as syphilis (Braunstein, Bass, and Thomas, 1940), tuberculosis (Beheyt and Vandeputte, 1958), rheumatic carditis (Crawford, 1943), trauma (French, 1912), or myocotic embolism (Pirani, 1943) are responsible. The most common cause of left ventricular aneurysms is myocardial infarction (Schlichter, Hellerstein, and Katz, 1954), but occlusive coronary artery atherosclerosis and thrombosis are exceptionally rare in both Nigerians (Abrahams et al., 1962) and other Africans (Becker, 1946; Lurie, 1960). With one exception (Lurie, 1960), major coronary artery occlusion has not been found in cases with typical annular subvalvular aneurysms, and in Lurie's patient, a 31-year-old African man, it is uncertain whether the thrombosis in the left circumflex artery, which was stretched over a large submitral aneurysm, preceded or followed the formation of the aneurysm. The electrocardiogram was normal. Angiocardiography in our Nigerian case showed filling of both coronary arteries, and though the circumflex branch of the left coronary artery was stretched, as has been noted in other cases (Lurie, 1960; Abrahams et al., 1962), it was not occluded. In any event, it is doubtful 
whether coronary insufficiency in the area supplied by this artery would produce the pattern of antero-lateral ischæmia present in this case. All the Nigerian cases hitherto encountered had nonspecific electrocardiographic changes and none presented with ischæmic pain or an electrocardiogram of myocardial infarction (Abrahams et al., 1962). However, other reported cases with the same type of aneurysm, usually situated antero-laterally, have had similar electrocardiograms to Case 1, with deeply inverted T waves in leads I, VL, and V4-V6 (Brink and Barnard, 1954; Lurie, 1960; Schrire and Barnard, 1963), which have been attributed to infarction (Lurie, 1960), or to "extensive left ventricular damage" (Schrire and Barnard, 1963). In view of the rarity of severe coronary artery disease in Africans and the fact that these subvalvular aneurysms are herniations through the atrio-ventricular ring and are without muscle in their walls, this particular electrocardiographic pattern is difficult to explain.

Coronary artery thrombosis in Case 2 is extremely unlikely in the absence of hypercholesterolæmia, arteritis, or any other precipitating factor. Though the electrocardiogram resembled that of posterior myocardial infarction it did not show the usual pattern of evolution and at no time did the patient experience ischæmic chest pain. Since cardiac aneurysms are almost invariably secondary to myocardial damage, it is usually difficult to separate the electrocardiographic pattern from that of the underlying infarction. Persistence of the S-T segment elevation some weeks after a myocardial infarction is usually accepted as evidence in favour of the development of an aneurysm, and Schlichter et al. (1954) found persistent S-T segment elevation in leads II, III, and VF in patients with posterior aneurysms. It seems possible that in our case the posterior aneurysm might account for the unusual electrocardiogram without having to invoke a preceding cardiac infarct. Evidence in support of this is provided by the case of an 8-year-old girl with a postero-lateral aneurysm and similar less marked electrocardiographic changes (Beheyt and Vandeputte, 1958).

There are no diagnostic auscultatory signs of cardiac aneurysm; systolic and diastolic murmurs (Schlichter et al., 1954; Abrahams et al., 1962; Schrire and Barnard, 1963), and diastolic gallop sounds (Schlichter et al., 1954) are frequently present. Less commonly, systolic gallops or clicks have been noted (Reid and Humphries, 1955; Levine and Harvey, 1959). The mechanism of these extra sounds is unknown, and Levine and Harvey (1959) suggest that they may be due to the systolic expansion of the aneurysm striking against the chest wall. LeRoy and Roberts (1941) described the case of a 52-year-old coloured man with a mid-systolic click and an aneurysm which arose at the site of the attachment of the anterior papillary muscle. They postulated that the click was produced by a sudden reflux of blood into the left atrium as the result of stretching of the papillary muscle and distortion of the anterior mitral leaflet. Another case with a systolic clicking sound and a submitral aneurysm (Hollander and Crawford, 1940), in whom necropsy was subsequently performed, showed no abnormality of valve cusps or chordæ (Burn et al., 1943).

Mitral incompetence is commonly found in association with annular subvalvular aneurysms and has been attributed to stretching of the valve ring by large submitral aneurysms (Abrahams et al., 1962). This is probably the mechanism of the mild regurgitation present in Case 1. However, Case 2 had small aneurysms and yet considerable mitral incompetence was demonstrated on both angiocardiograms. Since these aneurysms arise immediately below the valve and are therefore intimately related to papillary muscles, chordæ tendineæ, and valve cusps, it is possible that they may interfere with valve closure and cause mitral regurgitation by this mechanisn. In all the cases previously described the murmurs of mitral incompetence have been pansystolic, and the association of aneurysms with late systolic murmurs has not yet been documented. Late systolic murmurs without early vibrations demonstrable by the phonocardiogram have been shown to indicate mitral incompetence, usually mild (Barlow et al., 1963). They are frequently associated with a mid- or late systolic click (Lian, 1948; McKusick, 1957; Barlow et al., 1963). It has been suggested that both click and the late systolic murmur of mitral incompetence are produced by slight deformity of the valve cusps or chordæ which is usually the result of previous rheumatic endocarditis (Reid, 1961; Barlow et al., 1963). Because the regurgitation is very slight, these patients are symptomless and have normal electrocardiograms and chest radiographs. Humphries and 
McKusick (1962) have described 11 patients with late systolic murmurs associated with abnormal electrocardiograms showing low, diphasic, or inverted T waves in leads II and III. Several of these patients also had systolic clicks. They referred to this association as "characteristic electrocardiographic-auscultatory syndrome", and postulated that it was related to a previous pericarditis. These unusual electrocardiographic and auscultatory features were present in our second case and the syndrome may therefore not be as benign as has been thought. By means of left ventricular angiography, Barlow et al. (1963) conclusively demonstrated mitral incompetence in all their patients with late systolic murmurs. They considered that this procedure was probably not justifiable in the investigation of future patients with late systolic murmurs, but that prophylaxis against subacute bacterial endocarditis and recurrent rheumatism should be instituted, as in any patients with rheumatic heart disease. However, in view of our experience any patients with the association of a late systolic murmur and abnormal electrocardiogram should undoubtedly be investigated by left ventricular angiography in order to exclude a submitral aneurysm or abnormality of similar location, since the prognosis and managements are likely to be very different.

The ætiology of these annular, subvalvular aneurysms is still unknown. A congenital weakness of the atrio-ventricular ring having possibly a racial genetic basis has been suggested (Abrahams et al., 1962). Though we cannot be sure that the lesion in the European boy is identical to that found in Negro patients, the clinical evidence strongly favours this, and therefore disposes of the racial limitations of these aneurysms.

\section{SUMMARY}

Subvalvular left ventricular aneurysms of unknown ætiology are described in two youths, a Nigerian and a European. One of these had angina and both presented with electrocardiograms suggestive of myocardial infarction.

Submitral aneurysms, because of their close association with valve cusps and chordæ, may be the cause of systolic clicks and late systolic murmurs, and of electrocardiographic abnormalities. The significance of this syndrome in relation to diagnosis and treatment is discussed.

We are very grateful to Professor J. F. Goodwin for his help and encouragement in the preparation of this paper. We wish to thank the staff of the Department of Medical Illustration for the illustrations and Mrs. A. Cartwright for secretarial assistance.

\section{REFERENCES}

Abrahams, D. G., Barton, C. J., Cockshott, W. P., Edington, G. M., and Weaver, E. J. M. (1962). Annular subvalvular left ventricular aneurysms. Quart. J. Med., 31, 345.

Barlow, J. B., Pocock, W. A., Marchand, P., and Denny, M. (1963). The significance of late systolic murmurs. Amer. Heart J., 66, 443.

-, and Shillingford, J. (1958). The use of amyl nitrite in the differentiation of the systolic murmurs of aortic stenosis and mitral incompetence. Brit. Heart $J ., 20,168$.

Becker, B. J. P. (1946). Cardio-vascular disease in the Bantu and Coloured races of South Africa. S. Afr. J. med. Sci., 11, 1.

Beheyt, P., and Vandeputte, M. (1958). L'anévrisme ventriculaire, d'origine tuberculeuse, chez des jeunes Africains. Acta cardiol. (Brux.), 13, 419.

Berlin, R., and Hallén, L. (1938). Ein Fall von Herzaneurysma mit seltener Lokalisation. Acta med. scand., 95, 34.

Braunstein, A. L., Bass, J. B., and Thomas, S. (1940). Gummatous myocarditis and aneurysm of the left ventricle. Amer. Heart J., 19, 613.

Brink, A. J. and Barnard, P. J. (1954). Syphilitic aneurysm of the left ventricle of the heart with calcification and ossification. S. Afr. med. J., 28, 476.

Burn, C. G., Hollander, A. G., and Crawford, J. H. (1943). Rare cardiac aneurysm in a child. Amer. Heart J., 26. 415.

Clearkin, K. P., and Bunjé, H. (1955). Rare cardiac aneurysm in a young adult. Thorax, 10, 42.

Corvisart, J. N. (1813). A Treatise on the Diseases and Organic Lesions of the Heart and Great Vessels, trans. C. H. Hebb. Underwood and Blacks, London.

Crawford, J. H. (1943). Aneurysm of the heart. Arch. intern. Med., 71, 502.

Endrys, J., and Bártová, A. (1962). Pharmacological methods in the phonocardiographic diagnosis of regurgitant murmurs. Brit. Heart J., 24, 207.

French, H. (1912). A case of traumatic aneurysm of the heart of a child aged three, resulting from a fall from a third storey window to the ground, producing no definite cardiac symptoms during life but leading to sudden death by spontaneous rupture on the twentieth day after the accident. Trans. med. Soc. Lond., 35, 245. 
Higginson, J., and Keeley, K. J. (1951). An unusual cardiac aneurysm in a young adult. J. clin. Path., 4, 342.

Hollander, A. G., and Crawford, J. H. (1940). Unusual configuration of the heart in a child. Amer. Heart J., 20, 762.

Humphries, J. O., and McKusick, V. A. (1962). The differentiation of organic and "innocent" systolic murmurs. Progr. cardiovasc. Dis., 5, 152.

Hunter, W. C., and Benson, R. L. (1933). Rare form of saccular cardiac aneurysm with spontaneous rupture. Amer. J. Path., 9, 593.

LeRoy, G. V., and Roberts, R. C. (1941). Systolic gallop rhythm as a sign of aneurysm of the left ventricle. Amer. Heart J., 21, 115.

Levine, S. A., and Harvey, W. P. (1959). Clinical Auscultation of the Heart, 2nd ed. Saunders, Philadelphia and London.

Lian, C. (1948). The use of the phonocardiograph in clinical cardiology. Brit. Heart J., $10,92$.

Lurie, A. O. (1960). Left ventricular aneurysm in the African. Brit. Heart J., $22,181$.

Martin, N. H. (1946). An intramural cardiac aneurysm. J. Path. Bact., 58, 297.

McKusick, V. A. (1957). Symposium on cardiovascular sound. Circulation, 16, 414.

Pirani, C. L. (1943). Erosive (mycotic) aneurysm of the heart with rupture. Arch. Path., 36, 579.

Reid, J. A., and Humphries, J. O. (1955). Systolic clicks (so-called systolic gallops): A study of their clinical significance. Bull. Johns Hopk. Hosp., 97, 177.

Reid, J. V. O. (1961). Mid-systolic clicks. S. Afr. med. J., 35, 353.

Robertson, J. H., and Jackson, J. G. (1960). Cardiac aneurysms in Nigeria. J. Path. Bact., 80, 101.

Schlichter, J., Hellerstein, H. K., and Katz, L. N. (1954). Aneurysm of the heart: A correlative study of 102 proved cases. Medicine (Baltimore), 33, 43.

Schrire, V., and Barnard, C. N. (1963). The surgical cure of a cardiac aneurysm of unknown cause. J. cardiovasc. Surg. (Torino), 4, 5 .

Vogelpoel, L., Nellen, M., Swanepoel, A., and Schrire, V. (1959). The use of amyl nitrite in the diagnosis of systolic murmurs. Lancet, $2,810$. 